\title{
Parental Involvement and Academic Performance of High School Students with Solo Parents in a Catholic School
}

\author{
Emelito L. Valencia ${ }^{1}$ and Johnny T. Roberto ${ }^{2}$ \\ ${ }^{1}$ St. Blaise High School, Inc., Antique, Philippines \\ ${ }^{2}$ Pandan Bay Institute Inc., Pandan, Antique, Philippines
}

\begin{tabular}{l} 
Article history \\
Submitted: 6 July 2020 \\
Revised: 6 November 2020 \\
Accepted: 12 November 2020 \\
\hline Keywords: \\
Education \\
Management \\
Parental Involvement \\
Academic Performance \\
Solo Parents, Catholic School \\
Descriptive-Correlational \\
Antique
\end{tabular}

students' academic performance and the relationship between these two variables.

Introduction. Parental involvement is the foundation of a child's education that has been recognized to positively impact students' academic outcomes. However, a lack of parents' support and involvement in the children's education persist in a catholic school in the Philippines. It leads to issues concerning its role in children's academic performance with solo parents. Thus, this study describes the extent of involvement of solo parents based on Epstein's framework covering parenting, communicating, volunteering, learning at home, decision-making, and collaborating in relation to their demographics. It also describes the level of academic performance of high school students with solo parents in a Catholic school during the School Year $2019-2020$ as a whole and according to the academic level. It also explores the differences in the extent of involvement and level of the

Methods. The study employed a quantitative research design using descriptive-comparative and correlational approaches to measure the solo parents' participation in their children's education and determine if there is a relationship between parental involvement and student academic performance. The respondents were the entire population of 62 high school students with solo parents of a Catholic school in the province of Antique for the School Year 2019 - 2020. The data were gathered using the questionnaires of Wulandary and Herlisa (2017), Shute (2009), and Corrigan (2002). The students' academic performance was measured through their General Periodic Average (GPA). Mean, Standard Deviation, Independent Samples T-test, One-Way Analysis of Variance (ANOVA), and Pearson $r$ were used to analyze the data.

Results. The findings revealed a great extent of parental involvement across all variables, including age, sex, income, and educational attainment. In terms of Epstein's types of involvement, their parental involvement in parenting, volunteering, decision-making, and collaborating was to a great extent; however, their involvement in communicating and learning at home was moderate. When grouped according to the demographics, the older, female, high income, and college graduate groups had a higher extent of involvement than their counterparts. In terms of Epstein's six types of involvement, the younger, female, high income, and college groups had a higher extent of involvement in parenting. In terms of communicating, the older, female, high income, and college groups had a higher extent of involvement. In volunteering, the older, male, high income, and college groups had a higher extent of involvement. In learning at home, the older, female, high income, and elementary groups had a higher extent. In decision making, the young, female, high income, and college groups had a higher extent. In collaborating, both sexes had the same extent of involvement. In contrast, the female, high income, and college groups had a higher extent. As for the students, their level of academic performance was very satisfactory, with the senior students having a higher GPA over the junior students. Furthermore, comparative data revealed that in terms of sex, there was a significant difference in parenting; in terms of income, there was a significant difference in parenting; and, in terms of educational attainment, parenting, communicating, volunteering, and decision-making. For the rest of the areas and variables, no significant difference in the extent of involvement was observed. Post hoc test revealed that parents with high income have significantly higher parenting involvement than those of other income categories. The college graduates have significantly higher parenting and decision-making than other parents. There was no significant difference regarding the level of academic performance of high school students when they are grouped according to 
the academic level. Finally, there was no significant relationship between parental involvement and academic performance.

Conclusion. Generally, solo parents actively participated in their children's education. They participated more often regarding parenting, volunteering, decision-making, and collaborating than in communicating and learning at home, most likely because of their economic status. Among the variables, educational attainment influenced their involvement in parenting, communicating, volunteering, and decision-making. In contrast, their income influenced their parenting, and their sex influenced their collaborating involvement. It is further concluded that the students do well academically despite their academic level and their solo parents. Finally, the parents' extent of involvement was not a factor in the students' academic performance; thus, they can achieve academic success regardless of their parents' extent of involvement in their education.

Practical Value of the Paper. This study will enhance the existing local literature on parental involvement based on the six types of parental involvement by Epstein and the increasing issues on solo parenthood. The findings of this study likewise served as the basis for improving the school system concerning parent involvement by developing a parental involvement program $/ \mathrm{s}$ to help improve students' academic performance.

\section{References}

Bartolome, M. T., Mamat, N., \& Masnan, A. H. (2017). Parental Involvement in the Philippines: A Review of Literatures. International Journal of Early Childhood Education and Care, 6, 41-50.

Corrigan, A. (2002). Parent-Teacher Involvement Questionnaire: Parent version. Retrieved on January 10, 2018.

Delmonte, L., Gabon, R., Gabon, V., \& Dela Cruz, J. (2014). Home Management Practices of Solo Parents in Samar, Philippines. Countryside Development Research Journal, 2(01), 73-77.

Epstein, J. L. (2010). School/family/community partnerships: Caring for the Children We Share: When Schools Form Partnerships with Families and the Community, the Children Benefit. These Guidelines for Building Partnerships Can Make It Happen. Phi Delta Kappan.

Farooq, M. S., Chaudhry, A. H., Shafiq, M., \& Berhanu, G. (2011). Factors affecting students' quality of academic performance: a case of secondary school level. Journal of quality and technology management, 7(2), 1-14.

Georgiou, S. N. (2007). Parental involvement: Beyond demographics. International Journal about Parents in Education, 1(0), 59-62.

Ibrahim, A. T., \& Jamil, H. B. (2012). The Nature of Parental Involvement in the Schooling Process in Katsina State. Journal of Education and learning, 1(2), 37-50.

Shute, V. J., Hansen, E. G., \& Underwood, J. S. (2009). Untying the knot: Review of personal research on the influence of parental involvement on student's academic achievement at the secondary school level. In the ETS Research Report.

Wulandary, D. \& Herlisa. (2017). Parental Involvement in Schooling Processes: A Case Study in Aceh School. University of Tampere.

\section{Correspondence:}

Emelito L. Valencia [evalencia18@yahoo.com.ph]

http://orcid.org/0000-0002-8192-2896 